This is a self-archived version of an original article. This version may differ from the original in pagination and typographic details.

Author(s): Gomes Silva A. Parada, Filomena; Young, Richard A.

Title: Using Contextual Action Theory for conceptualization and research on adolescent development

Year: 2019

Version: Accepted version (Final draft)

Copyright: (c) The Authors, 2018.

Rights: In Copyright

Rights url: http://rightsstatements.org/page//nC/1.0/?language=en

Please cite the original version:

Gomes Silva A. Parada, F., \& Young, R. A. (2019). Using Contextual Action Theory for conceptualization and research on adolescent development. In L. B. Hendry, \& M. Kloep (Eds.), Reframing Adolescent Research (pp. 78-96). Routledge.

https://doi.org/10.4324/9781315150611-5 


\section{Using Contextual Action Theory for Conceptualization and Research on Adolescent Development.}

\section{Filomena Parada University of Porto and University of Jyväskylä and Richard A. Young University of British Columbia}

Recently, scholars' calls for psychology to move beyond traditional ways of conceptualizing and researching human behaviour have increased. Contextual Action Theory (CAT) is a conceptual, methodological, and practical framework that is consistent with these calls. In CAT action is conceptualized as a complex, dynamic, and multidimensional system that can be comprehended from multiple levels of organization and from multiple perspectives. The Action-Project Method (A-PM) is the research method that emerged from CAT. It is a qualitative, naturalistic, process-oriented, longitudinal methodology that has been used to study joint, goal-directed actions and projects. The focus of data gathering and analysis is the thorough description and understanding of people's actions as they are constructed in daily living. To illustrate how CAT has been used to conceptualize the design of research and the A-PM to reflect that design, we present an integration of findings from several recent studies on the transition to adulthood that used the theory and the method.

\section{Authors' bios}

Filomena Parada UNIVERSITY OF JYVÄSKYLÄ, FINLAND, is a MSCA Individual Fellow (Project Reference: 749313 - TeenEduGoals), since June 2016. Previously, she was a researcher at the Centre for Psychology at University of Porto. Between 2009 and 2015, she was a Post-Doctoral Fellow at the University of Coimbra and spent some time working as a Filomena Parada is a Marie Skłodowska-Curie Actions Individual Fellow. Project title Adolescents' education transitions: Multiple insights into the process dynamics of goalconstruction and youth actions over time. Project Reference: 749313 - TeenEduGoals. 
Visiting Post-Doctoral Fellow at the University of British Columbia (Canada). Her main research interests are youth transitions to work and adulthood and positive youth development. Contextual Action Theory, career counselling and development, and lifelong learning are among her topics of specialization. She has 18 peer-reviewed publications (journal articles and book chapters/monographs), 153 citations and an h-index of 5 (Google citations index).

Richard A. Young UNIVERSITY OF BRITISH COLUMBIA, CANADA, is Professor of Counselling Psychology and holds the Myrne B. Nevison Professorship in Counselling Psychology. He is a Fellow of both the Canadian Psychological Association and the American Psychological Association and a Registered Psychologist in British Columbia. His current research interests include the application of action theory and the qualitative actionproject method to a variety of research topics, including the transition to adulthood, families, career development, counselling, health, and suicide. His most recent co-edited book, addressing the application of action theory to counselling practice, is book is Counseling and action: Toward life-enhancing work, relationships, and identity (R. A. Young, J. F. Domene, \& L. Valach, Eds., Springer-Science, 2015). 


\section{Introduction}

Scholars' calls for psychology to move beyond traditional ways of conceptualizing and researching human behaviour has increased in recent years. Contributions to this book are illustrative of such a trend and resonate with Kloep \& Hendry's (2014) appeal for "more radical strategies" (p. 1544) and conceptualizations that allow developmental research to overcome its current emphasis on individual processes. Raeff (2017) argued for the need for contemporary psychology to move beyond conventional assumptions and practices obstructing our ability to systematically understand and investigate the person from an integrative perspective. One way of overcoming some of the field's current limitations is to conceptualize the person as an integrated individual who acts and develops in relation to others in cultural practices. Such an approach requires directing psychologists' attention to the dynamics and the complexities of the ongoing, interrelated individual, social, and cultural processes that structure and organize action. According to Raeff, to acknowledge action, that is what people do as they go about "their particular lives in particular corners of the world" (p. 12), as psychology's subject matter, would help "bring the person back into psychology" (p. 9). It would also provide psychologists with a common language for collaboration both across disciplines and across psychology's fragmented areas of conceptualization and research.

Consistent with this call for new conceptualizations and methods to address human change, Young, Valach and colleagues (e.g., Domene, Valach \& Young, 2015; Valach, Young \& Lynam, 2002; Young \& Domene, 2012; Young \& Valach, 1996, 2004; Young, Valach \& Collin, 1996, 2002) have proposed Contextual Action Theory (CAT). CAT is a conceptual, methodological, and practical framework that focuses on processes of action across time. Similar to other perspectives on human action (e.g., Balconi, 2010; Boesch, 2001; Bruner, 1990), CAT addresses how people engage in and make sense of their everyday lives. This conceptualization of action recognizes the significance of intentions and goals for human behaviour, the socially embedded nature of actions, and that actions both produce a person's social and cultural world and are a product of it. It also implies adopting a descriptive research stance to bring together "goal-directed, functional and causal explanations of actions in a way that captures context" (Young, Valach \& Domene, 2005, p. 216). 
In line with Kloep \& Hendry's (2014) appeal and with Raeff's (2017) argument, it is our aim to propose the perspective of contextual action as a systematic and integrated way of approaching conceptualization and research in human development. To that aim, first, we provide an overview of CAT and describe its associated research method, the action-project method (Young et al., 2005; Wall et al., 2016). Then, we use the transition to adulthood as an illustration of how CAT has been used to conceptualize the design of research and the actionproject method (A-PM) to reflect that design. We conclude by presenting an integration of findings from several recent studies on the transition to adulthood conducted by Young and colleagues (e.g., Young et al, 2008, 2011a, 2015, 2017). Findings from these studies demonstrate the unique contribution of CAT and the A-PM for an integrative, processoriented understanding of human action. They specifically describe the actions and projects in which young people engage as they navigate the transition to adulthood.

\section{The Perspective of Contextual Action: Human behaviour as an intentional, socially constructed process}

Young, Valach \& Collin (1996) originally introduced Contextual Action Theory (CAT) as an explicit explanation of career development. However, it was not designed solely as an explanation of development in the career domain. As Valach \& Young (2002) highlighted, the framework contains a "well-described image of the person and a conception of psychology" (p. 98) allowing us to characterize CAT as a general theory of goal-directed action in people's everyday life. Among the core premises of the theory is the notion that individuals both construct their lives through action and use action as a framework to understand their own and others' behaviour as intentional and goal directed. Action is defined as the intentional, individual and joint processes that are oriented toward achieving a desired end state or goal (Valach et al, 2002; Young \& Valach, 1996, 2004).

Action also is understood as a dynamic, open to change and changing system that is embedded in and with context. Context is not perceived as a setting or environment for action (e.g., Domene et al, 2015; Valach \& Young, 2002). Context and action are weaved together in such a manner that they can only be understood in relation to one another. Context is what allows people to make sense of all the goals, plans and intentions filling in 
the progression and sequencing of their actions. Human actions give relevance and substance to a person's life and embedded contexts. It is through action, and in particular through their sequencing over time, that individuals' connection to larger social contexts and culture is construed and becomes apparent.

In CAT, change appears as the product of the interactions or transactions between individuals and the social contexts they are embedded in, that is, of their actions and of how these actions unfold over time (e.g., Young et al, 2002). In this way, ontogenetic development is incorporated and can be understood as part of the ongoing action and context. From the perspective of contextual action, change or development result from the process of human action, specifically from the ways in which people make sense of or construct their lives over the lifespan, into ontogenetic development, by understanding the goal-directed nature of human actions and by linking together actions that have common or similar goals across time. Inherent to this process is a concept of action as a complex, dynamic, and multidimensional system that must be comprehended from multiple levels of organization and from multiple perspectives.

\section{Systems of action}

Individual action, joint action, projects and careers are the four systems of action identified by CAT (e.g., Domene et al, 2015; Valach et al, 2002). Actions are short or immediate, timespecific phenomena, anchored in our daily lives. Actions are energized by emotional processes, and maintain amongst themselves hierarchical relationships of super- and subordination towards goals, have a temporally ordered sequence, and different actions pertaining to different goals may coexist. Joint action refers to action people take together, that is, to a pair or group of individuals who are jointly engaged in achieving a goal or desired end state. As the focus is not on the interaction but on the action people take together, this concept of joint action is a "particularly notable and new way of addressing context" (Valach \& Young, 2002, p. 66).

Having a conversation with parents about one's college major or university one will attend, going out with friends, and taking cooking or driving lessons, are examples of joint actions in our daily lives. When several of these individual and joint actions coalesce over a mid-term length of time toward a goal, they are referred to as project. Projects are superordinate 
constructs that operate as heuristic systems enabling people to proceed toward their goals by exploring possibilities rather than following strict guidelines. A project ends usually when the goal or goals encompassing the actions comprised by the project are achieved. Similar to action, projects are typically thought of as jointly rather than individually construed. Joint project is defined as a series of goal-directed actions involving the person and other(s), over a mid-length period, for example, a day, weeks, months, or years (e.g., Young \& Valach, 1996, 2008). Choosing and/or training for an occupation, becoming friends or maintaining a friendship with someone, and learning to live independently are examples of projects people engage in.

When projects are constructed over a much longer period and encompass a wider range of actions, they are referred to as career. Career is a superordinate construct and the most complex system of action. It operates as a framework by which people represent their lives and ongoing involvement with that life in all significant domains of commitment.

Parenthood, friendship, marriage, occupation are examples of possible careers, that is, how over extended periods of time and by using feedback and feedforward processes, we organize and make sense of specific aspects and major domains in our lives. The systems of action, that is, action, project and career add a critically important longitudinal perspective to this conceptualization.

\section{Organization of action}

In CAT, action is organized as elements, functional steps, and goals. Goals, the highest level of organization of action, reflect the meaning or overall intentions of the person engaging in the action. It is through the goals that we know what an action is about. Goals are "imagined, striven-for and end states or processes" (Valach \& Young, 2002, p. 101) that arise in and through action. They allow the unit of action to be identified. Goals accompany and emerge from action; they are "a part of the action or project itself" (p. 103) rather than constituting ends people establish in advance of their actions. Action is what allows for goal enhancement and development. It is through the performance of an action that goals become operational.

To understand action we must also understand the flow and sequence of the action, that is, the means or functional steps a person uses in moving towards the goal. Functional steps are the 
medial level of action organization and consist of a sequence of contiguous elements that are oriented towards a common goal (e.g., Young \& Valach, 1996, 2008). The elements in the steps are observable and do not occur in isolation. They provide the structurally defined features of an action and can be measured systematically and precisely. Elements refer to both the specific behaviours, skills, habits and unconscious processes involved in an action, and the internal and external resources available or needed for executing the action. For example, engaging in a conversation with a parent may be a step directed towards the goal of coming to a decision about a higher education major. Sitting with the parent, asking questions, nodding one's approval, listening, giving and receiving feedback, are examples of elements that may be present in the action of a having such a conversation.

\section{Perspectives on action}

According to CAT, to accomplish a comprehensive and integrated understanding of action, project and career, a third dimension needs to be considered: the perspectives on action (Young \& Valach, 2008). Action can be understood from three perspectives: manifest behaviour, internal processes and social meaning. Manifest behaviour refers to the readily observable verbal and non-verbal behaviour involved in the action. These units of behaviour are plausible, immediately recognizable and subject to systematic observation. Talking, listening, arguing, and laughing are behaviours we can easily find in a conversation held by two people, like a parent and adolescent child.

Internal processes are the subjective, cognitive and emotional processes that steer, control and regulate action. Internal processes occur simultaneously with behaviour and serve feedforward and feedback functions. Feeling angry with or being understood by a parent, as well as doubting or trusting the parent's ability to help are examples of internal processes an adolescent may experience in response to the parent's action. Internal processes also contribute to the construction of social meaning, that is, the individually and socially meaningful explanations individuals construct about their own and others' actions. These social and cultural meanings shape action and are made operational in how a person generates his or her goals. For example, the way in which the adolescent describes to a friend his or her feelings during a conversation with a parent, and how, based on such description, the adolescent and friend construct the parent's ability to help their offspring. 


\section{The Action-Project Method: An alternative research method}

The Action-Project Method (A-PM) is a qualitative, naturalistic, process-oriented, longitudinal research method (Young et al, 2005; Wall et al, 2016). It is based on CAT and has been used for about two decades to study joint, goal-directed actions and projects. The method allows for the description of the joint actions and projects a person and those who are connected to them in some way engage in while addressing situations and events in their everyday lives. Although the A-PM was originally developed in the fields of vocational and health psychology, applications to other domains of research have been successfully executed, including: research with families and intimate relationships, for example, friendships, parent-child relationships; counselling and clinical psychology, for example, suicide, anorexia nervosa, bereavement, addiction, agency and unconscious processes in counselling; and the transition to adulthood (e.g., Domene \& Young, 2008; Marshall et al, 2012). As detailed descriptions of the method have been provided elsewhere (e.g., Marshall et al, 2012; Valach et al, 2002; Young et al, 1994; Wall et al, 2016), the main features and procedures and analysis are introduced briefly here.

\section{A-PM main features}

The A-PM differs from many other research methods in that its unit of analysis is the action rather than the individual. Here action is understood as a socially and culturally embedded process (Valach et al, 2002). The focus of much of the research using this method has been on dyadic joint action, such as a conversation. The method was designed to access the ways in which dyads jointly engage in actions across time. For example, how over a period of several months, young adults and those involved with them as parents, counsellors, peers, or romantic partners, jointly construct, articulate, and act on goals and strategies pertinent to the transition to adulthood. The projects emerging from these joint actions as well as the actions themselves are culturally grounded and contextualised. They have a content and a context in which they are constructed, and reflect how "we come to grips with the world while creating one ourselves" (Young \& Valach, 2004, p. 507). In CAT, actions and projects not only are 
impacted by culture but also contribute to the construction and the realization of culture (Young et al, 2011b).

Another distinctive feature of the A-PM is its emphasis on process and explanation (e.g., Valach et al, 2002). The purpose of the method is to explain or describe action rather than predict future behaviour. No strength or direction of relationship between variables is established, and no underlying cause for the differences observed between individuals is identified (Domene \& Young, 2008). Description is achieved by accessing the social, manifest and subjective processes underlying individual and joint actions. When using the method researchers' focus is not only on the content of the dyad's joint action, that is, what they are doing together, but also on how they are doing it, that is, how this pair of individuals actively engage with one another to achieve their goals over time. This focus requires that the actions and projects, both individual and joint, are monitored longitudinally and in such a way that accounts for joint goal-directed processes as they occur in everyday life. It also requires that observation is present-oriented, that is, the focus is on actions and intentions people are currently engaged in and not on what they state about wanting or intending on doing or becoming in the future (e.g., Valach \& Young, 2002).

The A-PM enables researchers to adapt procedures to the focus of the research. It is not a rigid protocol. Of central importance for implementing a study using the method is whether the research questions are answered in light of goal-directed action. As Marshall and colleagues (2012) highlighted, the A-PM "is particularly suitable for studying topics that are inherently goal oriented, such as transitions or decision-making processes" (p. 170). Typically, research questions are directed towards the identification and description of patterns of action occurring within a sample. However, case studies or multiple case study approaches have also been used, as well as between-groups comparative analyses (for a discussion, see: Domene \& Young, 2008).

\section{Procedures and analysis}

Data gathering and analysis involve multiple procedures to access information from three perspectives on action described above (manifest behaviour, internal processes, and social 
meaning) (e.g., Young \& Domene, 2012). Data are collected longitudinally, for example, over a period of 9-10 months in some studies, at several data collection points. Multiple data collection points are critical for the study of process-oriented phenomena such as those pertaining to the actions that people jointly engage in over a period of time, to address specific situations or events in their lives that have one or more common goals (e.g., Young et al, 2005). Data gathering and analysis within dyads occur concurrently (Domene \& Young, 2008; Young et al, 2005; Wall et al, 2016).

Data collection consists of the following steps:

(a) Video recording of an initial conversation or joint action between participants, and accessing internal processes of action through a video playback interview;

(b) Identifying a project based on the joint action of the conversation;

(c) Sharing that project identification with the participants and seeking their affirmation or modification of it at a narrative feedback session;

(d) Monitoring of the identified project over typically 6 months (though other periods of time have been used); and

(e) A final joint conversation.

Both the initial and the final conversation follow a similar procedure, which includes (a) a warm-up conversation, that is an unstructured introductory interview that has the aim of initiating participants in talking about the topic of the research study; (b) a 10- to 15-minute video-recorded conversation about the topic participants have chosen, without the researchers being present; and (c) a self-confrontational procedure.

During the self-confrontation each participant separately views the video-taped playback of the action with one of the researchers, and is asked to report on thoughts and feelings experienced while engaging in the joint action with the other dyadic member (Young et al, 1994). The premise is that by unpacking participants' thoughts, feelings and sensations through the self-confrontation, researchers have access to how participants are steering, 
controlling, giving meaning and often regulating their actions (for a discussion of the assumptions and principles underlying the self-confrontation procedure, see Valach et al, 2002; Young et al, 1994, 2011b). Data collected during the initial and final conversation is usually supplemented by telephone monitoring. Other types of data such as personal diaries can also be used (Young et al, 2005).

Coinciding with data collection, an analysis of the initial and final conversation takes place following each one of these two meetings for each dyad. The aim of the analysis of the initial conversation is to identify the dyad's joint project to be shared with participants during the narrative feedback session (e.g., Wall et al, 2016). The final individual case analysis consists of a compilation of the analysis made for each dyad. Through this case analysis the dyad's actions and projects are identified. Emerging constructs and themes that reflect the dyad's actions and projects are subsequently identified.

Identification and description of the dyad's actual and superordinate projects are reached through a process of consensus decision-making that involves, first, consensus between the pair of researchers who collected the data for the respective dyads; second, agreement with the research team; and finally, consensus with the participants at the second data gathering session. Analyses are conducted according to a "consensus based, hermeneutic analysis strategy" (Young \& Domene, 2012, p. 25) involving a continuous interaction between theory and observation that requires researchers to continuously move back and forth between data and the theoretical framework (Young et al, 2005). This strategy requires that no assumptions are made. Cross-case analysis follows individual case analysis. Analysing across cases allows researchers to identify the actions and projects across the entire sample. It also allows for the identification of important themes that reflect these actions and projects for the sample.

\section{Transitioning to adulthood from the perspective of Contextual Action Theory: Conceptualization and findings}

Recently, the study of the transition to adulthood has become a topic "very much in vogue" (Northcote, 2006, p. 3). The specific set of socioeconomic, cultural, historic, and political conditions of contemporary Western societies have had a direct impact on how young people approach and live their lives, including the processes they engage in making the transition to 
adulthood (Parada \& Young, 2013). As an extensive body of literature indicates, youth transitions to adulthood have become lengthier, more diverse and less predictable or linear, making the youth condition more protracted, with less clearly defined end markers, for example, getting married, becoming financially independent, moving out of parents' home (Arnett et al, 2011; Côté \& Bynner, 2008; Hendry \& Kloep, 2010). Thus, youth transitions involve greater subjective assessment.

These changed patterns and timing of the transition to adulthood, as well as their profound effects on youth experiences and pathways have led scholarly discourses around the topic to change from a rather static, outcome and person-centred perspective to a more fluid, context and process-oriented understanding that encompass change over time (Young, 2016). Nonetheless, as the concerns expressed by Kloep \& Hendry (2014) highlighted, much of the research on the topic does not adequately address the complexity and multi-dimensionality of the issues faced by young people while making their transitions to adulthood. In general, much of the existing research also does not adequately account for the intrinsic contextual nature of such transitions and of human change processes. As Young (2016) noted, such issues go beyond what can be simply understood as ontogenic development or change. They are more adequately addressed by what Brandtstädter $(1999$, p. 4) described as "enacted intentions", that is, individuals' active responses linked to the self-regulatory and selfreflective processes through which people act on their own development. Frequently the enactment of these intentions involves both youth and other actors such as parents or peers. Thus, and in line with CAT proposals, to better understand the processes young people engage in while becoming adults, we need to consider both youth themselves and those who are important to them and with whom they jointly address transition-related events and experiences. We also need to consider how young people join in with important others in enacting intentions pertaining to the transition to adulthood (Young, 2016; Young et al, 2011b).

\section{The transition to adulthood as an intentional, joint-goal directed process}

Adopting the perspective of contextual action implies engaging in a theoretical and empirical process directed toward a full understanding and descriptions of how joint actions between individuals coalesce over time to construct transitions towards adulthood projects (Young et 
$a l, 2011 b)$. In other words, it implies recognizing that the transition to adulthood does not result from a single event. Rather, the transition to adulthood is a process composed of several relevant sub-projects that can occur over several years. Furthermore, it is a socially constructed process through which youth, and those involved with them, engage in a series of actions perceived as meaningful for the achievement of one or more aspects of becoming adult. The perception of these actions as meaningful by the persons involved in them helps to guarantee that all significant projects and respective subprojects are and will keep on being identified and attended to during the time youth take to complete the transition to adulthood. Some projects and sub-projects will be maintained while others will be abandoned or put on hold. Some projects are not effective in the transitional process and others fail because of factors such as skills or lack of resources (Hendry \& Kloep, 2002). Through the description of the social, manifest and subjective processes underlying individual and joint actions, CAT enables understanding of the meaningfulness of these actions, as well as how during the transition to adulthood youth and those involved with them adopt, modify, maintain, or abandon shared goals.

Over time, it is this process of project co-construction and sequencing that allows young people to become aware of existing connections between current and past actions. This process also allows youth to project themselves toward the future - a skill essential for the development of one's personal sense of meaningfulness and coherence over the long term (Young et al, 2011b). Thus, given the complexity and dynamism that underlies these processes, it is very hard "to conclusively describe a successful transition from adolescence to adulthood by its outcomes" (Young et al, 2011b, p. 18). According to CAT, the focus should instead be directed to how youth and other important people in their lives are working toward that transition to adulthood. Such aspects concern the coordination and compatibility of projects; the quality of the relationship young people establish with significant others engaged in the co-construction of their transition projects, especially at the communication level; the quality of the steering processes being implemented, both at the emotional and cognitive level; the adequacy of control and regulation processes "designed to choose, maintain and revise the procedures, steps, strategies and plans" (Young et al, 2011b, p. 19) serving the desired goals; and the effectiveness of monitoring and energizing processes put into motion. 
In addition, the focus of the research can also be directed to the agentic processes that underlie individual and joint actions. As Young (2016) highlighted, current approaches to the transition to adulthood, even if inadvertently, tend to overlook individual agency - that is, the individual's contributions to their own development. Emphasis is often on the assessment of outcomes, for example, educational attainment or leaving home, as a function of social support, which often neglects individuals as goal-directed actors who participate in their own development. The emphasis on the assessment of outcomes neglects to address the social nature of transitional processes. As argued earlier, the individual has been the exclusive focus of too much of the developmental research effort (Kloep \& Hendry, 2014). Many perspectives also tend to treat the actions of other social actors as background information, or these perspectives do not sufficiently address the individual's interactions with others when studying transitions (Young et al, 2011b). By contrast, the integration of findings from several studies from the CAT perspective illustrates how young people and those involved with them jointly construct, articulate, and act on goals and strategies pertinent to the transition to adulthood.

\section{Joint-goal directed processes inherent to the transition to adulthood: An integration of findings}

To date, research using the A-PM to study the transition to adulthood has sought to describe and understand the intentional, goal-directed processes young people and their parents (Young et al, 2008), counsellors (Young et al, 2011a), and peers (Young et al, 2015) engage

in during the transition to adulthood. Additional studies have addressed: (a) the types of projects for future work and life together that young adults involved in a committed relationship jointly construct and pursue (Domene et al, 2012); and (b) the joint goal-directed actions and projects of parents, and siblings taking on parental roles, as young adults with intellectual or development disabilities (IDD) were making transitions to adulthood (Young et al, 2017). In all of these studies, attention to the description of findings was on the sample as a whole and on the main patterns of action identified across participants, that is, on important joint projects and on the superordinate joint transitional projects engaged in by participants (youth or parents) and those involved with them. 
Findings highlight the transactional processes and describe, at the level of goals, functional steps and elements, some of the unique processes through which youths co-construct projects with others pertaining to transitions to adulthood. By revisiting the original data sets of some of the studies mentioned above, researchers were able to further identify and describe: (a) goals, functional steps and parenting projects that emerged over the period of data collection (Marshall et al, 2011); (b) the ways mothers and daughters, in contrast to mothers and sons, engaged in transition to adulthood projects (Domene et al, 2011); and (c) how youths and their peers, engaged in friendship relationships, all played a role as identity agents (Parada $e t$ $a l$, 2015). Main findings are presented according to the clusters of projects identified across studies: relationships, identity, career promotion, governance transfer/preparing for adult life, balancing priorities/managing day-to-day events. The role of resources and how these may hinder or facilitate the achievement of participants' goals are also discussed.

Relationship projects. In line with CAT assumptions and the A-PM procedures, participants in these studies engaged in joint projects involving goal-directed processes specific to the dyadic relationship. Youth and significant other relationship projects (friendship, young adult couples' mutual relationship, parent-youth relationship, counsellor-youth relationship projects) were central to how youth developed as adults and planned for the future (e.g., Wall et al, 2016). Participants maintained and negotiated their relationships by intentionally making efforts allowing them to establish or maintain a positive relationship, which, in turn, reinforced or contributed to their mutual sense of connectedness or cohesion. For young adult couples engaged in a committed relationship these efforts reflected the couple's desire to move forward in the relationship to, for example, living together, becoming engaged, getting married, having children. With counsellors, young people engaged in relational projects directed toward both their association with the counsellor and with significant others outside of counselling, for example, family. These other relational projects were one of the most important topics addressed during counselling sessions (Young et al, 2011a).

Counselling relationships also provided young people with a means of finding themselves by allowing them to act in adult fashion, in ways that perhaps could not have been possible with their parents. 
In addition, some dyads were not able to jointly act in ways to maintain their relationship. In particular, Young and colleagues (2015) identified negotiating/dissolving friendship projects. During the data collection, there was a shift in the status or experience of the relationship between dyadic friends that led to less frequent contact between them. These contacts were often portrayed as unsatisfactory, with one attempting to reach out more regularly than the other. The relationship projects youth negotiated and maintained with important others in their lives often were intertwined or served as a backdrop for other actions and projects related to identity formation, governance transfer, and career promotion. Relationship projects were also identified in parental dyads for youth going through a transition to adulthood (Young et al, 2017). These projects were about connecting for mutual support. Further, Marshall et al. (2011) observed that some parents in Young et al. (2008) study were engaged in maintaining a relationship despite a possible physical separation from offspring as they entered adulthood. Across studies, relational projects often occupied a superordinate position thus illustrating not only the particular importance of relationships in (young) people's lives, but also the ways in which longer term projects, such as the one of becoming an adult - or supporting one's young offspring to become an adult -, are promoted and realised socially.

Providing support and listening to one another, specifically operating as a source for emotional support and regulation for one another, participating in problem solving, affirming one another by sharing experiences and perspectives and receiving validation or working together to create a shared understanding are among the main functional steps identified for relationship projects. Having fun and being 'silly' together is a distinctive feature of how young people and their peers maintain or negotiate their friendships. In the relationship with their children, mothers attempt to maintain a relationship despite physical separation by adjusting the way they relate to their progeny and by managing emotions that emerged as they anticipated or experienced young people's departure from home (Marshall et al, 2011). However, as Domene and colleagues (2011) noted, there are striking differences in how mothers and daughters and mothers and sons engage with each other as they pursue transitional projects. Overall, mother-daughter dyads appeared to work more intentionally and closely together, and to experience lower levels of conflict than mother-son dyads. As 
Domene and colleagues argued, their findings may "reflect a broader pattern of how mothers tend to interact with their daughters versus their sons" (p. 284), and question whether the differences in communication and conflict identified in the study are responsible for some of the gender differences described in the literature.

Identity projects. Young and colleagues (2008) described the joint projects of youth and their parents as broadly referring to the development of youth's identity and social inclusion in the adult world. Although present, identity in parent-youth projects emerged more implicitly than in the relationships youth established with counsellors and peers. In their relationships with peers and counsellors, young adults had the opportunity to explore who they had been, are, and anticipate being in the future, that is, their identity (Wall et al, 2016). Both friendships and the counselling relationship enabled youth to adopt and discard roles and actively make sense of themselves. In other words, the relationships young people maintain with friends or counsellors are an "important vehicle in which the self-construction project is enacted" (Young et al, 2011a, p. 332). The counselling relationship offered youth a context that facilitated their enactment with different views of themselves, as well as an opportunity for the construction of a relationship that has characteristics set apart from other relationships in their lives. These goals were achieved by means of providing youth with affirmation and support, and the opportunity to disagree with the counsellor. Through the self-confrontation young people were also able to see themselves as constructing their identity, namely by seeing themselves as one who disagrees with the counsellor.

Parada and colleagues (2015) revisited Young and colleagues (2015) study to explore how young people and their peers, who engaged in goal-directed, intentional joint action, act as identity agents. Findings from Parada et al.'s study identified two main projects through which peers acted as identity agents: personal and friendship identity projects. Personal identity served as a backdrop for other actions and goals relating to friendship projects. Participants worked on their personal identity projects by providing feedback or supporting one another while envisioning themselves in the future or gained an understanding of how they individually situated themselves in comparison to others (e.g., peers, close friends, parents). They co-constructed friendship identity projects by reflecting and differentiating their friendship from other relationships and agreeing over what made them unique. 
Additional steps in friendship identity projects included supporting one another, reassuring and reaffirming their shared values, beliefs and norms that allowed them to balance fun and familiarity with respect and integrity.

Career promotion. Career promotion projects, that is, navigating and exploring educational choices or the pursuit of specific occupational choices, with parents, counsellors and peers were for the most part secondary projects identified by Young and colleagues in their studies (Wall et al, 2016). In their conversations career issues were often the main topic and/or starting point addressed by young people and their significant others. However, that appeared to be subordinate to relationship and identity projects, although it was manifest at the level of goals and sub-goals for several dyads in the studies. Interestingly, only motherdaughter dyads explicitly engaged in transition to university projects (Domene et al, 2011). Although a shared interest in the pursuit of studies at the higher education level was identified in mother-son dyads, no clear goals indicating the dyad was actively addressing this transition were identified. To achieve career promotion goals, young people, their parents, counsellors and peers took steps, such as working together to support the young person in reaching academic or career goals, including pursuing studies and being an athlete simultaneously, or deciding what major study to follow. Additional steps taken by participants concerned helping the young person to become more committed and motivated.

Similar to the relationships young people established with parents, peers and counsellors, young adult couples also engaged in joint actions directed toward the pursuit and implementation of career plans (Domene et al, 2012). These career projects focused on one or both dyadic members. They also appeared to be motivated by participants' desire to support one another while finding employment, achieving their occupational aspirations, and making or pursuing educational plans. Distinctive in these projects was the priority participants gave to their partners' happiness and aspirations. The sense that partners were able to pursue their aspirations was sometimes as important for participants as their own career plans and ambitions. Couples engaged in numerous activities with that aim in mind, for example, actively listening to one another, using humour and verbally supportive language, or engaging in physical gestures of support and affection. 
Governance transfer/preparing for adult life. Young and colleagues' (2008) study identified a parent-youth project directed toward enabling youth to become increasingly responsible for themselves. Young people and their parents often involved in actions pertaining to the transfer of responsibility over different domains of young people's life from parent to youth, that is, governance transfer projects. Enabling the young person to become increasingly more responsible for themselves was the underlying goal to these projects. These projects usually began with the identification, either individually or jointly, of salient jurisdictional domains, such as taking responsibility for judging the morality of one's behaviour or applying to university, and progressed to numerous focused joint actions that included asking questions, teaching, sharing opinions, and filling out applications. Main functional steps included sharing knowledge and developing skills, for example, applying for a credit card, asking questions to test adult thinking or negotiating, re-negotiating or arguing the transfer process. Striving for child-environment fit and pressing for acceptable change are parenting projects that could be seen as more explicitly supporting governance transfer.

Striving for a better fit between their children and the environment was achieved by parents by: (a) forecasting what they thought would change and/or what their children would need to accomplish to become adults; (b) coordinating the 'fit' between their child and the environment, either by modifying their current and future parenting to support their children, or by altering the context, for example, schooling or work, to provide a better fit with their children; and (c) using observations and feedback to assess whether actions they and/or their children engaged in generated a child-environment fit promoting the youths' transition to adulthood (Marshall et al, 2011). Pressing for acceptable change resulted from parental perceptions that their expectations toward their son/daughter did not agree with the youth's behaviour and goals. Further, based on their previous experiences with their son or daughter, parents felt that their child should be able to align their behaviour to parents' expectations. Such conviction allowed parents to maintain their expectations. Stepping back and stepping up were the strategies used by parents to motivate the adolescent. Stepping back involved being supportive while giving up control of the new responsibilities taken by the youth. Stepping up, involved telling the young person how to approach problems and giving advice about future goals. 
Projects of parents, or siblings taking parental roles, of young adults with IDD included equipping the young adult for adult life. The underlying goal of actions comprised by this project was to support the young adults to develop independence, find employment, establish friendships and/or find romantic partners, and ensure safety. As Young and colleagues (2017) noted, in some cases, the equipping project focused only on a specific domain, for example, finding employment or social relationships. In other cases, the equipping project was multifaceted with parents helping the young adult develop in several areas. For example, independence projects were often closely intertwined with safety projects as the promotion of independence was often accompanied by concerns about the young adult safety. Functional steps varied according to the specific focus of parents' actions, with prioritizing, planning, collaborating, problem-solving, as well as teaching/coaching, monitoring, and rewarding strategies all being used. Happiness with successes, often mixed with worries or concern, as well as learning to navigate the system were additional steps these parents engaged in with the aim of preparing their young adult children for adulthood.

Balancing priorities/managing day-to-day events. For young adult couples in Domene and colleagues' (2012) study, career was just one amongst other life priorities. Each couple's specific project was closely connected to different superordinate projects, for example, goals concerning the pursuit or implementation of career goals were combined with goals concerning the decision of where to live or how to develop their relationship. In other words, these couples were attempting to manage or balance multiple priorities in their lives. The priorities included: weighing up present and future needs, for example, spending versus saving money; combining roles in different life domains, for example, career and family; or the timing of specific life events such as having a child. Concomitantly, several of the parents, or siblings taking parental roles, of young adults with IDD also engaged in projects directed toward managing day-to-day while preparing for the future (Young et al, 2017). These parents engaged in a series of complex, often competing actions that required them to address simultaneously some level of present- focused management of daily necessities, difficulties and stresses, and preparing for their own future and those of their young adult offspring. 
Balancing the management of daily household needs with the immediate needs of their young adult children was one of the strategies used by parents (Young et al, 2017). Addressing the young adults' needs usually required parents to interact with various agencies to secure funding, housing and other support for the young adult. These parents were highly aware of how the future would look like when they would no longer be able to take care of their children. In addition, they often felt fatigued and overwhelmed by the resources required by the obligation of acting as major caregivers for their children. The amount of time and financial resources they were required to put in made them ponder the possibility of delaying other transitions in their own lives and careers, including the transition to retirement. Frequently, being the main caregivers of a young adult with IDD also conflicted with these parents' need to attend to their other children or grandchildren.

Resources. Across studies, the availability of resources emerged as a crucial dimension in how participants engaged in the diverse transition to adulthood projects described here. For example, financial constraints "appeared as an intrusive feature of many young couples' lives" (Domene et al, 2012, p. 23). These constraints informed the decisions of many young couples in a diversity of areas, such as buying a house or deciding to have children, wedding planning, choosing employment or considering further education, pursuing certain leisure activities like travelling. Similarly, financial constraints appeared as one of the main concerns of parents of young adults with IDD. As Young and colleagues (2017) highlighted, financial resources accounted for the degree to which parents were dependent on the system to find solutions for the future of the young adult, for example, securing permanent housing. Often, the financial concerns experienced by these parents added to their lack of knowledge or expertise about IDD or the system they were required to navigate. As noted above, communication and interaction difficulties were another barrier dyad members had to face and that to varying degrees influenced the progress of their joint projects (Domene $e t$ al, 2011; Young et al, 2008).

Lack of time was another barrier often experienced by dyadic members. Both for parentyouth dyads and young adults' and their peers the lack of time resulting from full and complex daily schedules emerged as an impediment to the progress of their joint projects. Proximity, and shared interests were other aspects with relevance to the ways in which friendship projects were enacted by young people and their peers (Young et al, 2015). As the authors noted, friendships with more abundant resources appeared to unfold differently from 
those lacking in resources. In particular, lacking in resources was frequently identified in friendships engaged in dissolution projects. Emotional resources were another important type of resource identified for both the parent-youth dyads and dyads of parents of youth with IDD (Young et al, 2008; Young et al, 2017). The more proactive or reactive ways in which dyadic members acted in situations, as well as their ability or commitment to improve negatively dysfunctional communications were additional factors hindering or facilitating participants' projects. Furthermore, the ability to connect to one another across multiple life domains and situations, appeared for many dyads across several studies as another important aspect facilitating progress or consolidation in their joint projects (Young et al, 2008; Young et al, 2017; Young et al, 2015).

\section{Conclusions}

Becoming an adult in contemporary Western societies involves several subjective assessments, on the part of the youth and of those involved with them, in navigating transitions to adulthood (e.g., Arnett et al, 2011). Findings from studies using CAT for conceptualization and research on 'transitions to adulthood' processes not only reflect the complexity of these processes but also provide an alternative way to understand the meaning of the transitions by young people and those involved with them socially and professionally, as well as by parents experiencing their adolescent's transitions. These findings "diverge considerably from the conceptualization and empirical research that focused on the structural aspects of the transition to adulthood" (Young et al, 2008, p. 305). Within CAT, these structural events and markers are understood as embedded and emerging from joint goaldirected processes between youth and others with whom they interact, such as parents, peers, counsellors, or romantic partners.

By focusing on joint action rather than on individual development, CAT addresses the social and contextual nature of human change process, of which the processes underlying the transition to adulthood are an important example. By focusing on how joint actions between individuals coalesce over time to construct projects and careers, CAT provides a conceptual connection between short-time and long-term embedding. The uniqueness of CAT's conceptual and methodological approach to the study of human change processes allows the theory and its associated research method to be offered as one way for psychology to move 
forward in the study of human development, including adolescent development. It also addresses many of the issues raised by contemporary calls for research to progress beyond traditional ways of conceptualizing and researching human development and develop more insightful ways of uncovering the processes and mechanisms of developmental change systemically at individual, group and societal levels, so that we can create psycho-social 'scaffolding' to enable optimal transitional 'pathways' from adolescence to early adulthood for all our young people.

\section{References}

Arnett, J. J., Kloep, M., Hendry, L. B., \& Tanner, J. L. (2011). Debating emerging adulthood: Stage or process? Oxford: Oxford University Press.

Balconi, M. (Ed.). (2010). Neuropsychology and the sense of agency. New York, NY: Springer Science.

Boesch, E. E. (2001). Symbolic action theory in cultural psychology. Culture \& Psychology, 7, 479 - 483. doi:10.1177/1354067X0174005.

Brandtstädter, J. (1999). The self in action and development: Cultural, biosocial, and ontogenetic bases of intentional self-development. In. J. Brandtstädter \& R. Lerner (Eds.). Action and self-development: Theory and research through the life span, (pp. 37-65). Thousand Oaks, CA: Sage Publications.

Bruner, J. (1990). Acts of meaning. Cambridge, MA: Harvard University Press.

Côté, J. \& Bynner, J. M. (2008). Changes in the transition to adulthood in the UK and Canada: The role of structure and agency in emerging adulthood. Journal of Youth Studies, 11, 251-268. doi: 10.1080/13676260801946464.

Domene, J. F., Nee, J. J., Cavanaugh, A. K., McLelland, S., Stewart, B., Stephenson, M., Kauffman, B., Tse, C. K. \& Young, R. A. (2012). Young adult couples transitioning to work: The intersection of career and relationship. Journal of Vocational Behavior, 81, 17-25. doi: http://dx.doi.org/10.1016/j.jvb.2012.03.005.

Domene, J. F., Socholotiuk, K. D. \& Young, R. A. (2011). The early stages of the transition to adulthood: Similarities and differences between mother-daughter and mother-son dyads. Qualitative Research in Psychology, 8, 273-291. doi: 10.1080/14780880903568022. 
Domene, J. F, Valach, L. \& Young, R. A. (2015). Action in counselling: A contextual action theory perspective. In R. A. Young, J. F. Domene \& L. Valach (Eds.), Counseling and action: Toward life-enhancing work relationships and identity (pp. 151-166). New York, NY: Springer. doi: 10.1007/978-1-4939-0773-1.

Domene, J. F., \& Young, R. A. (2008). Expanding the action project method to encompass comparative analyses. International Journal of Qualitative Methods, 7, 54-80. doi: $10.1177 / 160940690800700104$.

Hendry, L. B. \& Kloep, M. (2002) Lifespan development: resources, challenges and risks. London: Thomson Learning.

Hendry, L. B. \& Kloep, M. (2010). How universal is emerging adulthood? An empirical example. Journal of Youth Studies, 13, 169-179. doi: 10.1080/13676260903295067

Kloep, M. \& Hendry, L. B. (2014). Some ideas on the emerging future of developmental research. Journal of Adolescence, 37, 1541-1545. doi: 10.1016/j.adolescence.2014.09.002.

Marshall, S. K, Young, R. A., Stevens, A., Spence, W., Deyell, S., Easterbrook, A. \& Brokenleg, M. (2011). Adolescent career development in urban-residing aboriginal families in Canada. The Career Development Quarterly, 59, 539-558. doi: 10.1002/j.21610045.2011.tb00975.x.

Marshall, S. K., Zaidman-Zait, A., Domene, J. \& Young, R. A. (2012). Qualitative actionproject method in family research. Journal of Family Theory and Review, 4, 160 - 173. doi: 10.1111/j.1756-2589.2012.00117.x.

Northcote, J. (2006). Nightclubbing and the search for identity: Making the transition from childhood to adulthood in an urban milieu. Journal of Youth Studies, 9, 1-16. doi: $10.1080 / 13676260500523580$.

Parada, F. \& Young, R. A. (2013). Youth work transitions: A review with implications for counselling and career practice. Canadian Journal of Counselling and Psychotherapy/Revue canadienne de counselling et de psychothérapie, 47, 196-222.

Parada, F., Wilson, L. J., Green, A. R., Marshall, S. K. \& Young, R. A. (2015). Peers as identity agents. Exploratory study. Poster presented at the $17^{\text {th }}$ European Conference on Developmental Psychology. Braga, Portugal. September.

Raeff, C. (2017). Going where the action is to conceptualize the person. New Ideas in Psychology, 44, 7-13. doi: 10.1016/j.newideapsych.2016.11.006. 
Valach, L. \& Young, R. A. (2002). Contextual action theory in career counselling: Some misunderstood issues. Canadian Journal of Counselling, 36 (2), 97-112.

Valach, L., Young, R. A. (2004). Some cornerstones in the development of Contextual Action Theory of career and counselling. International Journal for Educational and Vocational Guidance, 4, 61-81. doi: 10.1023/B:IJVO.0000021138.12299.cf.

Valach, L., Young, R. A., \& Lynam, M. J. (2002). Action theory: A primer for applied research in the social sciences. Westport, CT: Praeger Publishers.

Wall, J. M., Law, A. K., Zhu, M., Munro, D., Parada, F., \& Young, R. A. (2016). Understanding goal-directed action in emerging adulthood: Conceptualization and method. Emerging Adulthood, 4, 30 - 39. doi: 10.1177/2167696815610695.

Young, R. A. (2016). Transitioning to adulthood as joint, goal-directed action. In J. Masdonati, M. Bangali \& L. Cournoyer (Eds.) Arrêt sur image! Perspectives contemporaines sur les parcours des jeunes (pp. 149 - 172). Québec, QC: Presses de L’Université Laval. Young, R. A. \& Domene, J. F. (2012): Creating a research agenda in career counselling: The place of action theory. British Journal of Guidance \& Counselling, 40, 15 - 30. doi: 10.1080/03069885.2011.620603.

Young, R. A., Marshall, S. K., Domene, J. F., Graham, M., Logan, L., Zaidman-Zait, A., Mart, A., \& Lee, C. M. (2008). Transition to adulthood as a parent-youth project: Governance transfer, career promotion, and relational processes. Journal of Counseling Psychology, 55, 297 - 307. doi:10.1037/0022-0167.55.3.297.

Young, R. A., Marshall, S. K., Foulkes, K., Haber, C., Lee, C. S. M., Penner, C., \& Rostram, H. (2011a). Counseling for the transition to adulthood as joint, goal-directed action. Journal of Vocational Behavior, 79, 325 - 333. doi:10.1016/j.jvb.2011.02.005

Young, R. A., Marshall, S. K., Stainton, T., Wall, J. M., Curle, D., Zhu, M., Munro, D., Murray, J., El Bouhali, A., Parada, F. \& Zaidman-Zait, A. (2017; online first). The transitions to adulthood of young adults with IDD: Parents' joint projects. Journal of Applied Research in Intellectual Disabilities. doi:10.1111/jar.12395.

Young, R. A., Marshall, S. K., Valach, L., Domene, J. F., Graham, M. D., \& Zaidman-Zait, A. (2011b). Transition to adulthood: Actions, projects, and counseling. New York, NY: Springer. doi:10.1007/978-1-4419-6238-6_1.

Young, R. A., Marshall, S. K., Wilson, L. J., Green, A. R., Klubben, L., Parada, F., Polak, E., 
Socholotiuk, K., \& Zhu, M. (2015). Transition to adulthood as a peer project. Emerging Adulthood, 3, 166 - 178. doi: 10.1177/2167696814559304.

Young, R. A. \& Valach, L. (1996). Interpretation and action in career counselling. In M. L. Savickas \& W. B. Walsh (Eds.), Handbook of career counseling theory and practice (pp. 361 - 375). Palo-Alto: Davies-Black.

Young, R. A. \& Valach, L. (2004). The construction of career through goal-directed action. Journal of Vocational Behavior, 64, 499 - 514. doi:10.1016/j.jvb.2003.12.012.

Young, R. A., \& Valach, L. (2008). Action theory: An integrative paradigm for research and evaluation in career. In J. Athanasou \& R. van Esbroeck (Eds.), International handbook of career guidance (pp. 643 - 658). New York: Springer-Science.

Young, R. A., Valach, L. \& Collin, A. (1996). A contextual explanation of career. In D. Brown \& L. Brooks (Eds.), Career choice and development, (pp. 477 - 512). San Francisco: Jossey-Bass.

Young, R. A., Valach, L., \& Collin, A. (2002). A contextual explanation of career. In D. Brown \& Associates (Eds.), Career choice and development (4th ed., pp. 206-250). San Francisco, CA: Jossey-Bass.

Young, R. A., Valach, L., Dillabough, J., Dover, C., \& Matthes, G. (1994). Career research from an action perspective: The self-confrontation procedure. The Career Development Quarterly, 43,185 - 196. doi:10.1002/j.2161-0045.1994.tb00857.

Young, R. A., Valach, L., \& Domene, J. F. (2005). The action-project method in counseling psychology. Journal of Counseling Psychology, 52, 215 - 223. doi:10.1037/00220167.52.2.215. 